\title{
Письменные источники на тибетском языке из фондов Национального музея Тувы
}

\author{
Рита П. Сумба \\ Национальный музей им. Алдан-Маадыр Республики Тыва, Российская Федерация
}

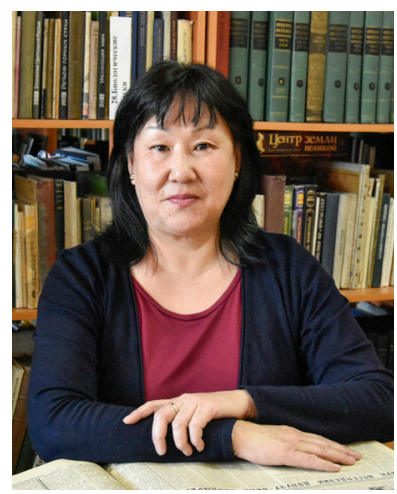

В фондах Национального музея Республики Тыва хранится коллекция рукописей и ксилографов на тибетском языке, которая насчитывает примерно 20000 единиц хранения. Статья рассматривает историю формирования и исследования коллекции, анализируются различные аспекты изучения тибетских рукописей и ксилографов. Источниками выступила внутренняя документация музея (книги поступлений) и ряд научных работ по теме.

Первое поступление предметов зафиксировано в 1954 2. Фонд пополнялся неравномерно, в разные годы и из разных источников, но все же можно предположить, что основная часть коллекции тибетских рукописей и ксилографов поступила из бывших библиотек буддийских монастырей Тувы.

Почти 80\% всей коллекции тибетских рукописей и ксилографов в фондах Национального музея в Туве составляют тексты культового и религиозно-обрядового содержания и труды буддийского канона. Один из них - редкий буддийский канон Ганджура, единственный в Туве. Был издан в Монголии, в Урге в 1908-1910 г2., найден в пещере в Кызылском районе, вероятно спрятанный во время репрессий священнослужителей 1930-х г2. Состоит из 94 томов и имеет 9 разделов. Представлены их названия на тибетском языке и санскрите.

Значительную часть тибетской коллекции в музее составляют небольшие по объему канонические сочинения из Ганджура в многочисленных изданиях-дубликатов. Отдельной группой является учебная литература, которая использовалась при изучении буддийской философии в монастырях. Ее не издавали в Туве, завозили из Бурятии и Монголии. Но тексты религиозно-обрядовой и бытовой практики издавали в печатнях крупных монастырях-хурээ Тувы. Мы можем судить об этом по коллекции резных ксилографических деревянных досок-клише, которые использовали для книгопечатания. Подчеркивается, что тем самым музейные коллекции проливают значительный свет на развитие буддизма в Туве.

Ключевые слова: памятник письменности; тибетский язык; Национальный музей Тувы; Тува; тибетская литература; ксилограф; буддизм Тувы; ургинский Ганджур; Ганджур de ORCID ID: 0000-0002-6296-2809

Sumba Rita Petrovna, Research Fellow, Department of Culture, Science and Religion, Aldan-Maadyr National Museum of the Republic of Tuva. Postal address: 30 Titov St., 667000 Kyzyl, Russian Federation. Tel.: +7 (923) 384-32-91. E-mail: risu1232001@yahoo.de 


\title{
Written sources in Tibetan language in the collections of the National Museum of the Republic of Tuva
}

\author{
Rita P. Sumba \\ Aldan-Maadyr National Museum, Republic of Tuva, Russian Federation
}

\begin{abstract}
Among the collections of the National Museum of the Republic of Tuva there are over 20000 archival units of manuscripts and xylographs in Tibetan language. This article examines the history of the collection, focusing on the various aspects of studying Tibetan xylographs and manuscripts. For its sources, the article relies on the museum's acquisition books and a number of research works on the topic.

The earliest items in the collection were acquired in 1954. Since then, it was expanded at irregular times, over several decades and from various sources. However, it would not be a mistake to suggest that the bulk of the collection came from the libraries of Tuva's disbanded Buddhist monasteries.

Religious and ritualistic texts, together with books of the Buddhist canon, account for up to 80\% of the collection of Tibetan manuscripts and xylographs in the museum's funds. One of them is a rare copy of the Kangyur Buddhist canon, the only one discovered in Tuva. It was made in Urga. Mongolia, in 1908-1910 and found in a cave in Kyzyl rayon - probably hidden during the anti-religious campaign of the 1930s. The copy consists of 94 volumes, categorized into 9 partitions (their titles in Tibetan and Sanskrit can be found in the article).

A large part of the Tibetan collection in the National Museum belongs to relatively small canonical works from the Kangyur in numerous reduplicating volumes. A separate group is found in the textbooks used in the monasteries for studying the Buddhist tradition. Never made in Tuva proper, it had been brought over from Buryatia and Mongolia. However, the texts of religious nature, as well as those dealing with ritual and everyday practice, were published at the printing shops of the largest Tuvan khuree (monasteries). This can be seen from a collection of a carved xylographic page boards which were used as a matrix for printing. Museum collections thus can be proved to have shed a lot of light on our understanding of the development of Buddhism in Tuva.
\end{abstract}

Keywords: monument of literature; Tibetan language; National Museum of the Republic of Tuva; Tuva; Tibetan literature; xylograph; Buddhism in Tuva; Kangyur of Urga; Kangyur

\section{For citation:}

Sumba R. P. Written sources in Tibetan language in the collections of the National Museum of the Republic of Tuva. The New Research of Tuva. 2019, № 2. URL: https://nit.tuva.asia/nit/article/view/850 (access date ...). DOI: 10.25178/ nit.2019.2.11

\section{Введение}

В настоящее время в Национальном музее им. Алдан-Маадыр Республики Тыва проходит каталогизация и описание тибетских рукописей и ксилографов, хранящихся в его фондах. Основной целью этой работы является история формирования и комплектации фонда, ввод тибетской коллекции в широкий научный оборот. Помимо них, в фондах хранятся: живопись, скульптура, предметы тибетской медицины, ритуальные принадлежности и коллекция монгольских рукописей и ксилографов. Всего более 5500 буддийских предметов.

Первое поступление и начало буддийской коллекции в хранилище Тувинского республиканского краеведческого музея им. Алдан-Маадыр (прежнее название музея), зафиксировано в инвентарной книге основного фонда № 1 от 1954 г., где описаны 372 единицы хранения. Коллекция включала в себя бронзовые статуэтки божеств, маски Цама, музыкальные инструменты, деревянные матрицы для печатания книг (Книга поступлений - КП № 1 (1145-28421). Возможно, эти предметы были сданы в музей из расформированных буддийских монастырей в Туве. В 1960 г. в музей поступила основная часть буддийских предметов из села Кызыл-Чыраа, Дзун-Хемчикского района, после упразднения юрт храмов. Здесь были конфискованы около 1500 предметов «буддийского культа и книги на тибетском и монгольском языках» (КП № 1 (1145-2842)).

\footnotetext{
${ }^{1}$ Номера предметов, которые находятся в книге поступлений № 1, здесь всего 372 предмета, от 1145 по 2842.
} 
При этом надо сказать, что коллекция монгольских рукописей и ксилографов (на монгольском и ойратском языках), которая в фондах НМРТ насчитывает 938 единиц хранения, более изучена (Сазыкин, 1992: 45). В 1983 г. коллекция была систематизирована А. Г. Сазыкиным, кандидатом филологических наук, научным сотрудником сектора тюркологии и монголистики Ленинградского отделения Института востоковедения АН СССР. Он описал название и краткое содержание каждого текста, указал объем страниц и размер (Бичелдей, 2011: 228).

Тибетский фонд музея располагает более 20 тысяч единиц музейного хранения. С начала поступления книг, сотрудниками музея фонд был приведен в порядок, коллекция была разобрана, изношенные барындаки (материя, в которые обвернуты книги) заменены на новые. Ксилографы и рукописи разложены по размерам. Были выделены три основных размера: ксилографы длиною менее 45 см; ксилографы длиною от 45 до 65 см; ксилографы длиною более 65 см. Размеры были выбраны, исходя из наиболее часто встречающейся длины ксилографов (Воробьева-Десятовская, Савицкий, 1981: 142).

С 1982 г. и последующие несколько лет, проведена первичная инвентаризация сотрудником Государственного музея истории религии и атеизма А. А. Терентьевым и искусствоведом отдела эстампов Государственной публичной библиотеки имени Салтыкова-Щедрина О. В. Горовой. Терентьевым была составлена бумажная картотека по алфавитному принципу, всего 915 карточек. На карточке отмечались инвентарный номер, название текста, количество листов и сколько текстов находится в томе, например, «Плюс 34 текста» (+ 34 тк.). Работа была очень кропотливая и велась «вручную», чтобы написать все названия текстов не было ни возможности, ни времени.

Целью данной статьи является восстановление истории формирования коллекции тибетских рукописей в Национальном музее Тувы, введение информации в научный оборот, а также анализ различных аспектов изучения тибетских рукописей и ксилографов.

\section{Буддийский канон Ганджура}

А. А. Терентьев и О. В. Горова в 1980-х гг. впервые обработали и зарегистрировали буддийский канон Ганджура, который представляет для исследователей большой интерес. Это единственный экземпляр, который сохранился в Туве. Был издан в Монголии, в Урге с 1908 по 1910 гг. под патронажем Его Святейшества Богдо-Гегена VIII.

Ганджур был найден в пещере Кок-Хая вблизи пос. Кунгуртуг Кызылского района, возможно, здесь он был запрятан во время событий 30-годов XX века, когда в регионе проходили массовые репрессии, в том числе священнослужителей. В 1970 г. Ганджур был доставлен в музей директором, М. Л. Делегом, заведующим отделом истории, старшим научным сотрудником М. Б. Кенин-Лопсаном и шофером музея Д. Адыг-Тулушем.

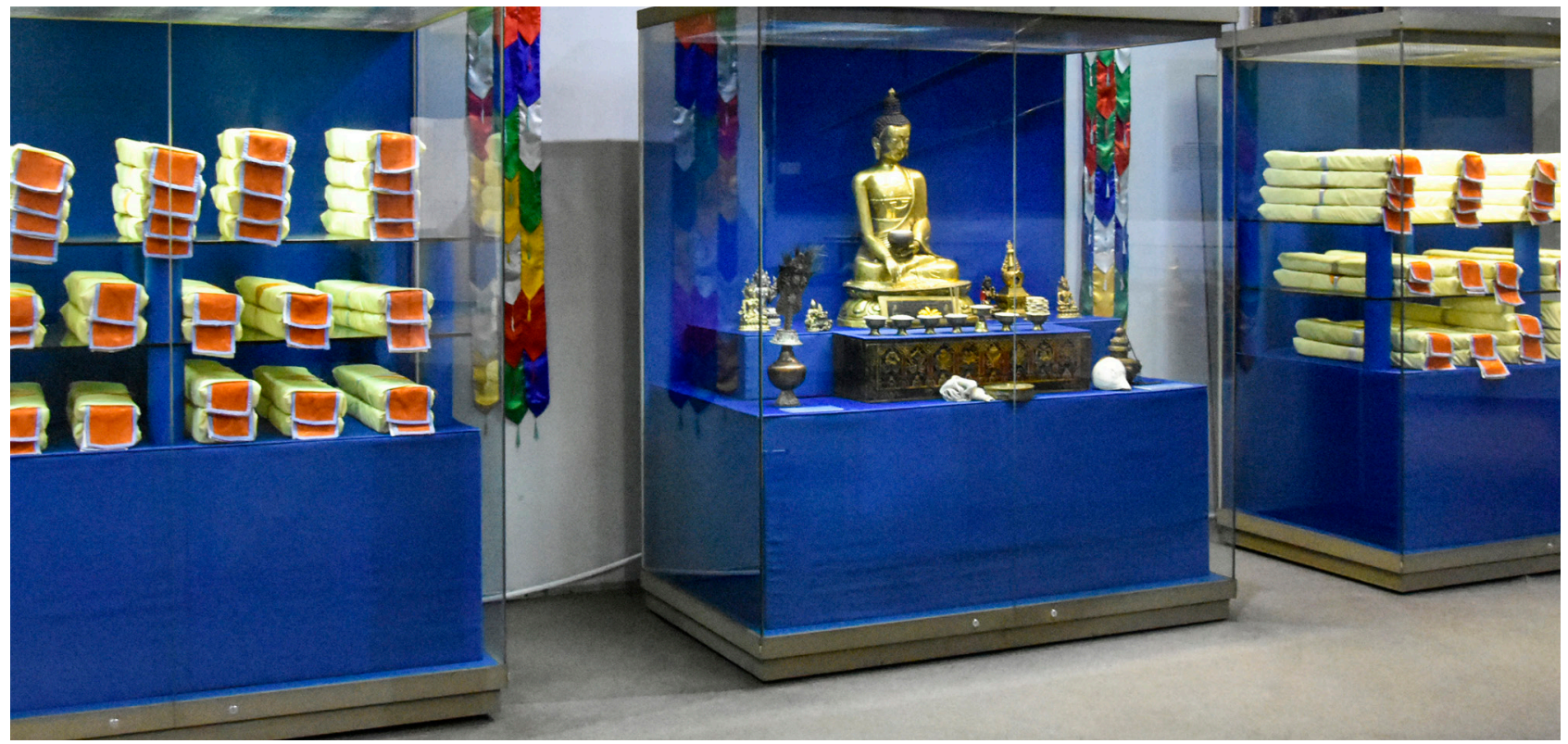

Фото 1. Ганджур в музее (в витринах слева и справа). Фото А. Д. Куулар, 2019 г. Photo 1. The Kangyur in the museum (on display left and right). Photo by A. D. Kuular, 2019. 
НОВЫЕ ИССЛЕДОВАНИЯ ТУВЫ

Www.nit.tuva.asia
№2

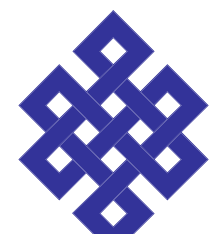

2019

\section{THE NEW RESEARCH OF TUVA}

Novye issledovaniia Tuvy

Последний в 2014 г. издал книгу, в которой вспоминает: «Пещера находилась в местечке “Хаалга”. Это труднодоступная, высоко расположенная пещера в горах, до которой добраться очень сложно. До нее мы спускались сверху, по отвесной горе, обмотав себя веревками. Вход в пещеру был завален лиственницей. Перед входом в пещеру мы совершили обряд воскурения, разожгли можжевельник, разложили пищу: жирное мясо, лепешки, саржаг-топленое масло и, молясь со словами: “хозяин горы, благослови”, сбросили деревья вниз. Внутри пещеры мы увидели деревянные сундуки, в которых лежали книги, длинные и большие размером. Каждая книга была обвернута материей в несколько раз и очень хорошо сохранились. В сундуках находились 140 книг» (Адыг-Тулуш, 2014: 152).

Долгое время Ганджур хранился в фондах музея без описи, и только в 1986 г. была создана картотека с указанием номеров по книге поступления КП № 7 (6939), год поступления 1971 г.), описаны тома, разделы, название на тибетском языке и на санскрите, количество страниц (фото 1, 2).

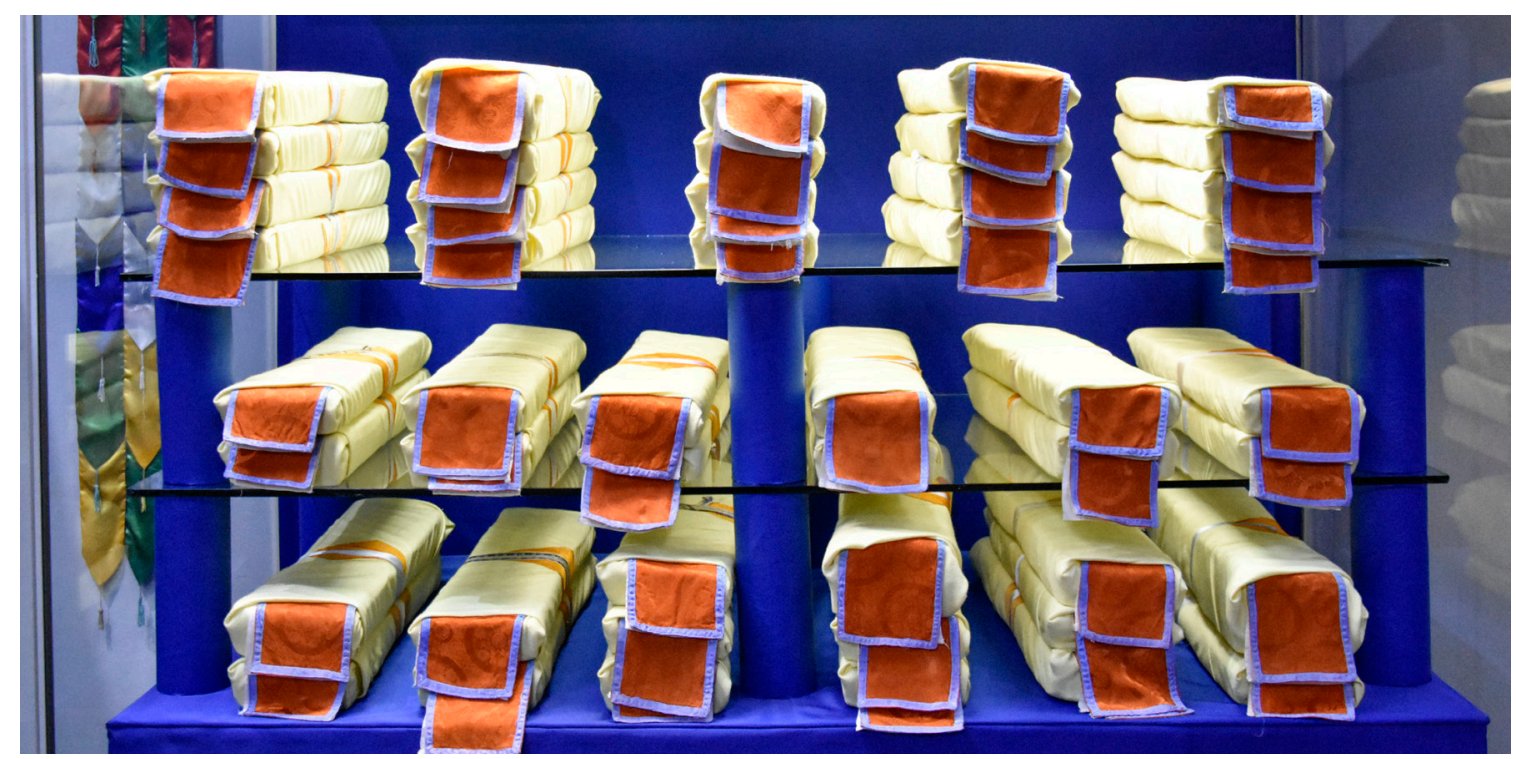

Фото 2. Свитки томов Ганджура в витрине музея. Фото А. Д. Куулар, 2019 г.

Photo 2. Scrolls of the Kangyur in a museum glass case. Photo by A. D. Kuular, 2019.

Ганджур состоит из 94 томов и имеет 9 разделов. Представим их.

1. Виная. Нравственная дисциплина. Основание. Раздел состоит из семи трактатов:

- Винаявасту (тиб. 'dul ba gzhi, санскр. vinaya-vastu). Содержит правила поведения монахов в общине. 4 тома;

- Протимокша-сутра (тиб. so sor thar pa'i mdo, санскр. pratimokshha-sūtra), том са. Сутра индивидуального освобождения;

- Винаявибханга (тиб. 'dul ba rnam par 'byed pa, санскр. vinaya-vibha nga) том cha, том пуа. Нравственная дисциплина;

- Бхикшунипратимокша-сутра (тиб. dge slong ma'i so sor thar pa'i mdo, санскр. bhikshhuni pratimokshasūtra и Бхикшунивинаявибханга (тиб. dge slong ma'i 'dul ba rnam par 'byed pa, санскр. bhikshhuñi-vinayavibha nga), том ta. Нравственная дисциплина монахинь;

- Винаякшудракавасту (тиб. 'dul ba phrang tshegs kyi gzhi, санскр. vinaya-kshhudraka-vastu), том tha, том da. Детализируется правила поведения монашества;

- Винаяуттарагрантха (тиб. 'dul ba gzhung bla та и 'dul ba gzhung dam pa, санскр. vinaya-uttara-grantha), том nа, том ра. Различные молитвенные тексты и благопожелания.

2. Праджняпарамита. О совершенстве мудрости в сто тысяч строф. Состоит из трех трактатов.

А) Большая праджняпарамита (тиб. shes rab kyi pha rol tu phyin pa stong phrag brgya pa, санскр. shhatasāhasrika-prajnyā-pāramitā) - О совершенстве мудрости в сто тысяч строф ('bum). 11 томов.

Б) Средняя праджняпарамита (имеет 3 варианта: большой, средний, сокращенный):

- Большой вариант. Панчавимшатисахасрика праджняпарамита (тиб. shes rab kyi pha rol tu phyin pa stong phrag nyi shu lnga pa, санскр. panyca-vimshati-sāhasrikā-prajnyā-pāramitā). Совершенство Мудрости, двадцать пять тысяч строф. 4 тома; 
- Средний вариант. Аштасахасрика праджняпарамита (тиб. 'phags pa shes rab kyi pha rol tu phyin pa khri brgyad stong pa zhes bya ba theg pa chen po'i mdo, санскр. ārya ashhTa-dasha-sāhasrikā-prajnyā-pāramitā-nāmamahāyāna-sūtra) Совершенство Мудрости, восемнадцать тысяч строф. 2 тома;

- Сокращенный вариант. Дашасахасрика праджняпарамита (тиб. 'phags pa shes rab kyi pha rol tu phyin pa khri ba zhes bya ba theg pa chen po'i mdo, санскр. ārya-dasha-sāhasrikā-prajnyā-pāramitā-nāma-mahāyānasūtra). Совершенство Мудрости, десять тысяч строф. 1 том.

В) Краткая праджняпарамита. Аштасахасрика праджняпарамита (тиб. 'phags pa shes rab kyi pha rol tu phyin pa brgyad stong pa, санскр. ārya-ashhTa-sāhasrikā-prajnyā-pāramitā). Совершенство Мудрости, восемь тысяч строф. 1 том.

3. Совершенство Мудрости - Компендиум в стихах (тиб. 'phags pa shes rab kyi pha rol tu phyin pa tshigs su bcad pa, санскр. ārya-prajnyā-pāramitā-sanycaya-gāthā).

4. Буддааватамсака (тиб. sangs rgya phal po che shes bya ba shin tu rgyas pa chen po mdo, санскр. buddhaavatamsaka-nāma-mahā-vaipulya-sūtra). Здесь трактуется понятие «Будда», приводится сведения о пантеоне махаяны, история рождения и жизни Будд. 3 тома.

5. Ратнакута - Собрание драгоценностей (тиб. dkon mchog brtsegs pa, санскр. ratnakūta). Ответы Будды на вопросы его учеников и дано описание местопребывания Дхьяни-Будд. 6 томов.

6. Сутра (тиб. mdo sde, санскр. sūtra). В разделе рассказывается об истории перерождений Будды. 31 том.

7. Сто тысяч тантр (тиб. rgyud 'bum ${ }^{1}$ ). Описывается четыре степени тантрийской мистики, мандалы различных божеств, техники жертвоприношений, приводятся молитвы, заклинания, гимны. 6 томов.

8. Тантра старых переводов (тиб. chos thams cad rdzogs pa chen po byang chub kyi sems kun byed rgyal po, санскр. sarva-dharma-mahā-santi-botthicitta-kulaya-rājā). 1 том.

9. Заклинание-дхарани (тиб. spyan 'dren rgyud gsum pa²). Собрание мантр и дхарани. 2 тома.

В дальнейшем в планах работы с буддийским каноном описание всех названий сочинений «тувинского» Ганчжура, которые входят в каждый том и по возможности, переводы этих названий.

Ургинское издание Ганджура имеется в библиотеке Международной академии индийской культуры в Нью-Дели (Индия). В научный оборот его ввел Локеш Чандра, индийский ученый, профессор. Он же дал подробные сведения на издание (Chandra, 1980). Гарчаг (оглавление полного собрания сочинения) этого комплекта Ганджура был опубликован Г. Бетленфальви (Bethlenfalvy, 1980). В России Ургинское издание Ганджура находится в Институте восточных рукописей РАН (Зорин, 2017), в Центре восточных рукописей и ксилографов ИМБТ СО РАН (Ванчикова, 2012: 243). Как нам сообщили из Санкт-Петербурга, по словам настоятеля дацана Гунцечойнэй Буда Бадмаева, еще один Ганджур Ургинского издания есть у них. Как мы полагаем, такое издание еще можно найти в Иволгинском дацане Улан-Удэ и в Монголии.

\section{Виды и типы тибетских рукописей}

Пополнение фондов музея тибетскими рукописями происходило разными путями, в том числе в виде поступлений от частных лиц. Бывали и случайные находки.

В книге поступлений НМ РТ зафиксированы интересные записи, раскрывающие историю предметов, хранящихся в фондах музея.

В 1971 г. в пещере Оораш-Хем Хаттыг-Тайга, Улуг-Хемского района, была найдена статуя Будды. Она была передана в музей Серен-оолом Сергеем Сатовичем (КП № 4 (5246), 13.04.1971 г.). Строитель колхоза «Мурнакчы», Санчы-оол Сарыг-Донгак также передал медную статую Будды, которую он нашел в пещере местности Шокар-Хая (КП № 3-4 (5267), время поступления предмета неизвестно).

В 1975 г. в музей была сдана глиняная статуэтка Будды и книги, принадлежавшие шаману-ламе Салчаку Самдану Доржуевичу. Предметы были найдены в пещере Кара-Суг-Мээзи Бай-Тайгинского района. В каком состоянии находились книги, на каком языке они были написаны, в книге поступлений не было никакой информации (КП № 5 (5997), 29.05.1974 г.).

В 1990 г. в музей были сданы две большие раковины, которые использовались в качестве музыкальных инструментов, сосуд для воды, маленький чайничек, колокольчик, жертвенные тарелочки из меди. Эти предметы были обнаружены местными жителями в пещере, в верховьях реки Суглуг-Хем. Среди этих находок находился документ на тибетском языке о регистрации скота с подписью Оюна Санчата, ламы из монастыря Эртине-Булак, который располагался близ села Межегей (Кривдик, 1990).

\footnotetext{
${ }^{1}$ Сочинения тиб. школы ньинма не переводят на санскрит.
}

${ }^{2}$ То же самое. 
НОВЫЕ ИССЛЕДОВАНИЯ ТУВЫ

www.nit.tuva.asia
№2

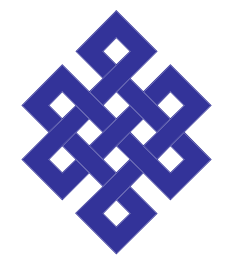

\section{THE NEW RESEARCH OF TUVA}

Novye issledovaniia Tuvy

Здесь необходимо вспомнить о том, что многие тувинские семьи традиционно имели в своих юртах и домах алтари со статуэтками Будд, божеств, книг на тибетском и монгольском языках. Иметь священные книги считалось благоприятным, поэтому многие тувинские семьи приобретали их, несмотря на дороговизну. В домашних библиотеках были популярны сочинения, относящиеся к буддийской философии: «Алдын-Херел», «Панчаракша», «Доржу Чотпа», «Чадамба» и т. д. Они имелись почти во всех семьях и часто приглашались ламы, которые зачитывали их, чтобы отвратить болезни и несчастья, для умножения скота и богатства (Сумба, 2004: 55; Sumba, 2005: 305). Подобная книжная повседневная жизнь отмечается и у бурят (Базаров, Ринчинов, 2016).

Однако, после того как в 1930 г. вышел правительственный указ, требующий добровольной сдачи культовых предметов и буддийской литературы (Монгуш, 2001: 114; Чыргалан, 2017: Электр. ресурс), многие жители прятали свои семейные реликвии в пещерах или закапывали в земле. Спрятанные таким образом книги не сохранялись, со временем плесень и сырость разъедала страницы, происходил полный распад бумаги. Некоторым семьям удавалось сохранить семейные раритеты и книги. Позже какаято часть попала в библиотеки или в архивы. Так, в Государственном архиве РТ находится небольшая коллекция книг на монгольском и китайском языках, также немногочисленна коллекция книг на тибетском и монгольском языках в библиотеке Тувинского института гуманитарных и прикладных социально-экономических исследований в г. Кызыле.

Многие предметы культа, статуэтки божеств и книги, были подарены в тувинский музей или переданы за вознаграждения частными лицами. Об этом свидетельствуют записи в книге поступлений НМ РТ: «В июле 1977 года были сданы 13 книг на тибетской письменности. Книги принадлежали Очиржапу Александру Дандаровичу, проживающим в селе Кара-Тал, совхоз «Дружба», Улуг-Хемского района» (КП № 7 (6841)); «Сутры на монгольском и тибетском языках, в количестве 27 штук, принадлежали Эртине Бурату Энеековичу из Кунгуртуга. Переданы в музей его сыном Санчаа Григорием Буратовичем», запись была сделана 11 июня 1978 года (КП № 7 (7097)); «Буддийские сутры (22 штуки), принадлежали Куулару Даваа Кежиковичу 1905 года рождения, село Баян-Тала, Дзун-Хемчикского района», акт закупочной комиссии от 25.09.80 г. (КП № 8 (7649)).

Почти 80\% всей коллекции тибетских рукописей и ксилографов в фондах Национального музея в Туве, составляют тексты культового и религиозно-обрядового содержания. Самые распространенные обрядники посвящены богине Палдан-Лхамо; восхваление и подношение Белой и Зеленой Таре; ритуалы божествам долголетия Амитаюсу и Ушнишавиджайе; дхарани и мантры для Белозонтичной Таре и божеству богатства Вайшраване. Подобную ритуальную и просветительскую литературу издавали в печатнях крупных монастырях-хурээ Тувы. Мы можем судить об этом по коллекции резных ксилографических деревянных досок-клише, которые использовали для книгопечатания.

На примере одного из таких экспонатов, который поступил в музей из буддийского монастыря Кызыл-Чыраа, Дзун-Хемчикского района, хорошо виден процесс создания досок. На одной из них вырезана только часть мантры «Ом-мани-падме-хум» на тибетском языке (КП № 3677/583, Буд - 411. Поступление: 21.06.1960). Остальной текст остался нетронутым и отчетливо видно, что он написан на бумаге, который наклеен на доску в зеркальном отображении. Для того чтобы отпечатать текст, доску покрывали тушью, накладывали бумагу и делали оттиск. Подобным образом печатали молитвы, мантры, обрядовые тексты (фото 3).

Известный ученый, Ю. И. Елихина, старший научный сотрудник Отдела Востока Государственного Эрмитажа, в 2016 г. изучала в фондах музея памятники буддийского искусства Тувы. Она отметила, что подобные работы демонстрируют не только высокий художественный уровень резьбы, но и умение передать сложные иконографические композиции и высокую грамотность тувинских лам (Елихина, Самосюк, 2015: 379). На ксилографической доске под номером (инв. № Буд-409), мантра «Ом-мани-

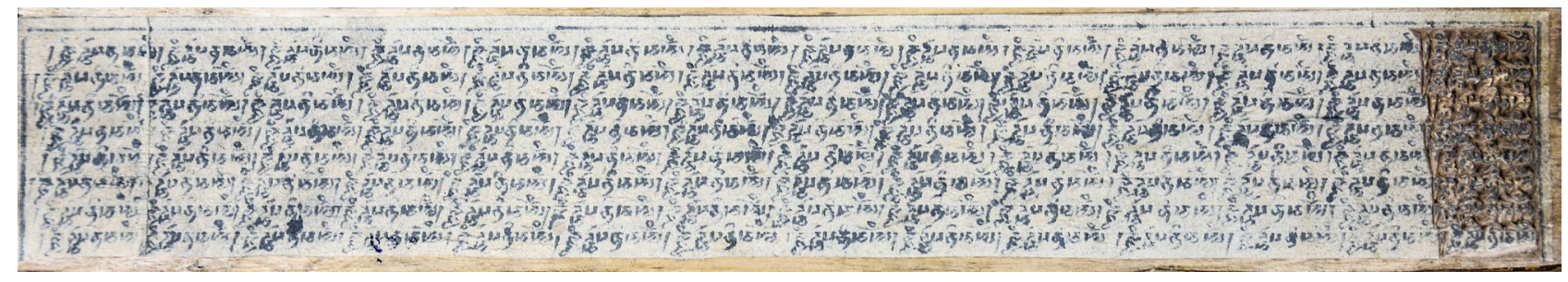

Фото 3. Деревянная матрица. Фото А. Д. Куулар, 2019 г.

Photo 3. A woodblock. Photo by A. D. Kuular, 2019. 
падме-хум» вырезана сразу на нескольких языках: на санскрите, тибетском, квадратным письмом, алфавитом ланчжа, монгольском и китайском, подобные мантры закладывались в молитвенные барабаны. На другой доске (инв. № Буд-469) вырезаны три божества долголетия: Белая Тара, Амитаюс и Ушнишавиджайя в зеркальном отображении. Культ Амитаюса был одним из самых распространенных. Тиражирование образов трех божеств долголетия ксилографическим способом свидетельствовало об особом их почитании в Туве (фото 4).

Значительную часть тибетской коллекции в музее составляют небольшие по объему канонические сочинения из Ганджура, которые представлены в многочисленных изданиях-дубликатов: «Сутра достижения счастья» ('phags pa bkra shis brtsegs pa); «Сутра тысяча Будд благой калпы» (bhadrakalpikā sūtra); Сутра, отвращающая все ссоры и опасности - «Успокоения черных скандалов» (kha mchu nag

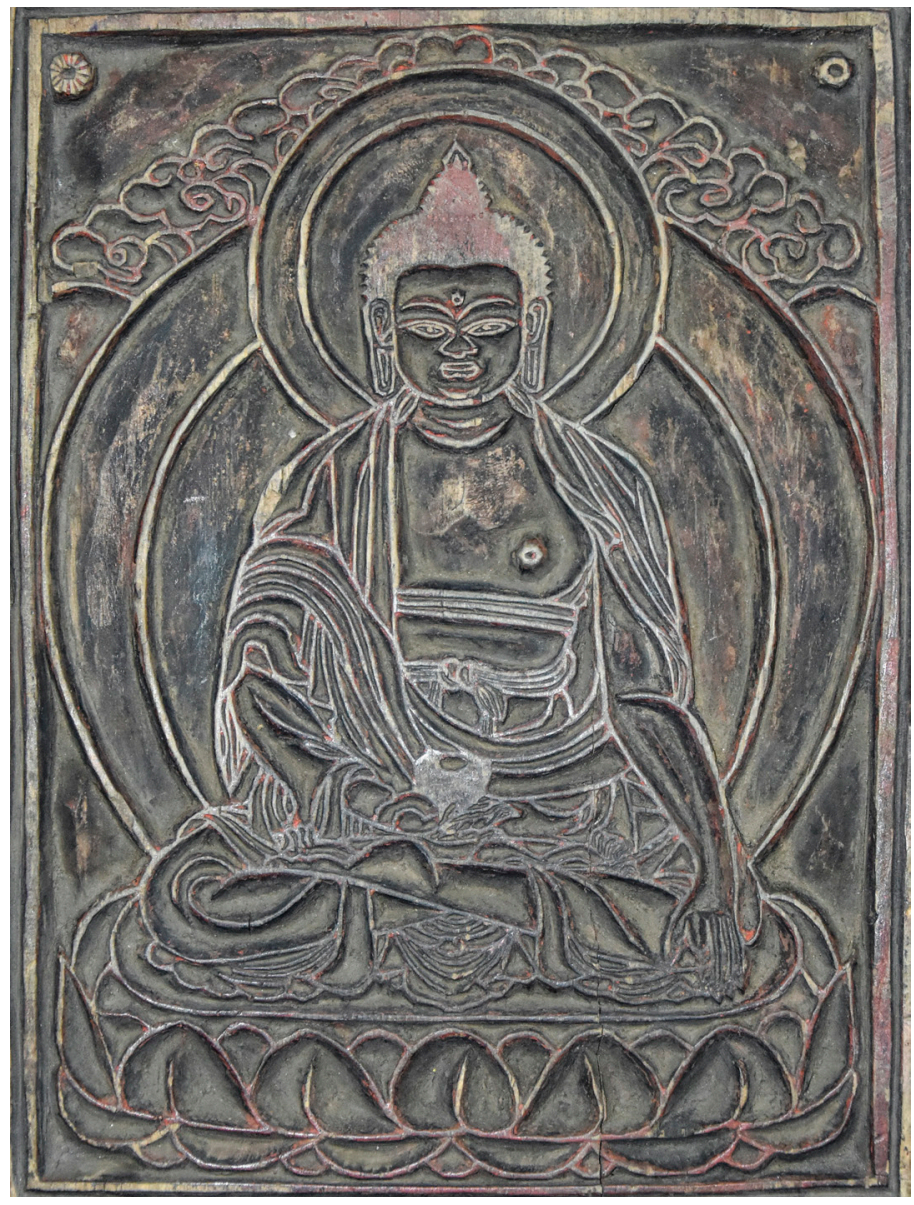

Фото 4. Деревянная матрица изображения Будды. Фото А. Д. Куулар, 2019 г.

Photo 4. A woodblock with an image of the Buddha. Photo by A. D. Kuular, 2019. po); «Сутра великого освобождения» (thar pa chen po); «Сутра три скопления» (phung po gsum pa); Сутра махаяны, «Безмерно долгая жизнь и превосходящая мудрость» (tshe dang ye shes dpag tu med pa). Многие умирают несвоевременно, но при ежедневном чтении этой сутры, у них появится возможность прожить еще 100 лет.

Богатое собрание этих сочинений хранится в Калмыцком институте гуманитарных исследований РАН (Музраева, 2010: 233), в Государственной библиотеке г. Берлина (Taube, 1966a: 47; 1966b: 787; 1966c: 1050); в библиотеке восточных рукописей Венгерской Академии наук (Catalogue of the Tibetan ..., 2008: 2, 256, 784); в Институте восточных рукописей РАН (Воробьева-Десятовская, Савицкий, 1974: 139-153; Зорин, 2014: 143).

Отдельной группой документов из фондов НМ РТ на тибетском языке можно назвать учебную литературу, которая использовалась при изучении буддийской философии в монастырях. На территории Тувы на 1928 г. существовало 26 монастырей (Монгуш, 1992: 126). При крупных монастырях возникали школы, где традиционно преподавались дисциплины: философия, логика, грамматика, медицина, астрология. Большая роль придавалась изучению философии, программа которой состоит из пяти основных предметов (Базаров, 2017) и коренных ${ }^{1}$ текстов к этим предметам.

На первом курсе таких школ изучали логику. Коренным текстом, по которому изучают эту дисциплину, являлся «Трактат о достоверном познании» (Праманаварттика - Краткий учебник логики), по сочинениям индийского философа VII в. Дхармакирти. По этому учебнику и в настоящее время обучаются в Гоман-дацане монастыря Дрепун, в монастырях Монголии и Бурятии. В фондах тувинского музея этого текста обнаружить не удалось, но есть комментарий на первую главу Праманаварттики - «Первая часть краткого учебника логики» (tshad ma rnam 'grel gyi tshig le'u byas pa bzhugs so) (3-43). И комментарий к работе Дхармакирти по логике: «Украшение семи разделов праманы» (tshad ma sde bdun rgyan yid kyi min sel).

На втором курсе изучалась литература по Праджняпарамите по базовому учебнику индийского ученого Майтреи-Асанги «Украшение полного постижения» (Абхисамаяламкара). Это сочинение имеет тибетское название: «shes rab gyi pha rol tu phyin pa'i man ngag gi bstan bcos mngon par rtogs pa'i rgyan». B

'Специальное название для источников или текстов по учебной литературе. 
фондах тувинского музея имеется несколько экземпляров этого сочинения (под номерами: 1-443, 3-11, 3-44).

В качестве коренного текста для третьего курса по Мадхъямике, теории «срединности», использовалась работа Чандракирти «Введение в мадхьямику» (Мадхьямакааватара). Тибетское название сочинения: «dbu ma la 'jug pa zhes bya ba bzhugs so», представлен в тувинском фонде в единственном экземпляре (3-11). В нем исследуется история философских систем и формирование различных школ Индии.

Наука о «высокой дхарме» (Абхидхармакоша) изучалась на четвертом курсе по работе легендарного проповедника буддизма, индийского ученого Васубандху «Сокровищница высшего учения» (тиб. chos mngon ba mdzod bzhugs so). Это сочинение (под номером 3-3) также находится в одном экземпляре. Здесь излагается строение и организация живого и неживого материального мира, религиозно-философское воззрение школ хинаянского направления (вайбхашиков и саутрантиков).

И наконец, на пятом курсе изучался «Кодекс монашеской дисциплины» Виная. Коренным текстом являлся «Корень обетов», индийского ученого VI в. Гунапрабхи. Этого текста в музее обнаружить не удалось. Но имеется сочинение Цзонховы (2-143): «Объединенная сущность море Виная» (тиб. 'dul ba rgya mtsho snying po bsdus pa), в котором предусматриваются устав и нормы поведения буддийской общины по «Ганджуру», приспособленные для школы Гелуг.

\section{Заключение}

Таким образом, тибетский фонд Национального музея Тувы, состоящий из более 20 тыс. единиц хранения, в основном состоит из обрядовых текстов, из текстов, которые использовались в храмовой, ежедневной службе. Фонд пополнялся неравномерно, в разные годы и из разных источников, но все же можно предположить, что основная часть коллекции тибетских рукописей и ксилографов поступила из бывших библиотек буддийских монастырей Тувы. Большинство из них были хорошо оснащены философско-схоластической литературой, учебными пособиями, словарями и дополнительной литературой тибетских, монгольских и бурятских авторов.

Состав музейных коллекций также косвенно говорит о том, что при монастырях-хурээ существовали печатные мастерские, были переводчики, лекари тибетской медицины, астрологи. Все это способствовало тому, что большинство семей были заинтересованы в обучении своих детей в буддийских монастырях - в то время единственных центрах образования. Большая часть литературы по философии, логике, медицине была привезена в Туву из Монголии, Китая и Тибета, где послушники края получали образование в буддийских университетах. И, конечно же, существовал свой класс тувинских ученых-лам, проповедников буддийского учения и лекарей.

Учитывая это, следует подчеркнуть: музейные коллекции проливают значительный свет на развитие буддизма в Туве, поэтому исследовательская работа по классификации, описанию хранящегося в Национальном музее республики коллекции представляется нам чрезвычайно важной.

В настоящее время ведется систематическая работа по научному описанию тибетского фонда, чтобы сделать его доступным для исследователей, ученых, востоковедов и широкой публике читателей. Предполагается выпуск небольшой части каталога, который будет включать информацию о примерно 500 единицах хранения.

\section{СПИСОК ЛИТЕРАТУРЫ}

Адыг-Тулуш, Д. К. (2014) Скиф хун турк уранхайнын хуулгаазын тывалары [Мистические тувинцы - скифы, хунны, тюрки Урянхая]. Кызыл : ООО «Кооператив «Журналист». 152 с. (На тув. яз.).

Базаров, А. А. (2017) Литература сиддханта (дубта) в бурятских монастырях на рубеже XIX-XX в // Востоковедение. T. 12. № 5. С. 105-111.

Базаров, А. А., Ринчинов О. С. (2016) Буддийская книжная повседневность Бурятии: Геоинформационные подходы к реконструкции культурного явления // Библиосфера. № 1. С. 11-18.

Бичелдей, У.П. (2011) Собрание буддийских рукописей и ксилографов в Фондах Национального музея Республики Тыва как памятник духовной культуры Тувинского народа // Память мира: Историко-документальное наследие буддизма. Материалы международной научно-практической конференции: сборник статей / отв. ред. В. В. Минаев. М. : Российский государственный гуманитарный университет. 229 с. С. 228-233.

Ванчикова, Ц. П. (2012) Буддологические исследования в Центре восточных рукописей и ксилографов ИМБТ СО РАН // Вестник Бурятского Научного Центра СО РАН. № 3 (7). С. 243-258. 
Воробьева-Десятовская, М. И., Савицкий, Л. С. (1981) Тибетский фонд ЛО ИВАН СССР // Письменные памятники Востока : Историко-филологические исследования. Ежегодник 1974. М. : Наука ; ГРВЛ. 139 с. С. $139-153$.

Елихина, Ю. И., Самосюк, К. Ф. (2015) «Обитель милосердия». Искусство тибетского буддизма : каталог выставки. СПб. : Издательство Государственного Эрмитажа. 379 с.

Зорин, А. В. (2014) Тибетский фонд Института Восточных рукописей РАН: Из истории формирования и каталогизации (1917-2013 гг.) // Страны и народы Востока / под ред. И. Ф. Поповой, Т. Д. Скрынниковой. М. : Наука, Восточная литература. 143 с. С. $143-168$.

Зорин, А. В. (2017) Каталог сочинений тибетского буддийского канона из собрания ИВР РАН. Вып. 1: Кагьюр и Тэнгьюр / под общ. ред. А. В. Зорина. СПб. : Петербургское Востоковедение. 512 с.

Кривдик, В. (1990) Тайна пещеры // Тувинская правда. № 23. С. 4.

Монгуш, М. В. (1992) Ламаизм в Туве. Кызыл : Тувинское книжное издательство. 126 с.

Монгуш, М. В. (2001) История буддизма в Туве (вторая половина VI -конец XX в). Новосибирск : Наука. 114 с.

Музраева, Д. Н. (2010) О составе и содержании коллекций буддийских письменных памятников, сохранившихся в Калмыкии к началу XX в // Память мира: Историко-документальное наследие буддизма. Материалы международной научно-практической конференции: сборник статей / отв. редю В. В. Минаев М. : Российский государственный гуманитарный университет. 233 с. С. 233-240.

Сазыкин, А. Г. (1992) Собрание монгольских рукописей и ксилографов из фондов Тувинского республиканского краеведческого музея им. 60 Богатырей // Тюркские и монгольские письменные памятники / отв. ред. С. Г. Кляшторный, Ю. А. Петросян. М. : Наука, Издательская фирма «Восточная литература». 151 с. С. $45-59$.

Сумба, Р. П. (2004) Шаманские тексты на тибетском языке в фондах Национального музея им. Алдан-Маадыр Республики Тува // Библиотеки в жизни общества, развитии науки и образования: материалы междунар. науч.-практ. конф. / отв. за вып. О. В. Фенцель. Кызыл : Вариант. 64 с. С. 55-58.

Сумба, Р. П. (2005) Тибетские рукописи и ксилографы в фондах Национального музея им. Алдан-Маадыр Республики Тува // 48th Permanent International Altaistic Conference, Moscow 10 - 15 July / Ed. by E. V. Boikova, R. B. Rybakov / Asiatische Forschungen, vol. 150. Wiesbaden : Harrassowitz Verlag. 353 c. S. 305-309.

Чыргалан, С. Ю. (2017) Буддийские монастыри в Туве до начала XX века [Электронный ресурс] // Молодой ученый. № 6. C. 384-387. URL: https://moluch.ru/archive/140/39539/ (дата обращения: 25.02.2019).

Bethlenfalvy, G. A (1980) Catalogue of the Urga Kanjur in the Prof. Raghuvira Collection at the International Academy of Indian Culture. Vol. 246 / њata-Pitaka Series: Indo-Asian Literatures. New Delhi : Published by International Academy of Indian Culture. $319 \mathrm{c}$.

Chandra, L (1980) A newly Discovered Urga Edition of the Tibetan Kanjur [Электронный ресурс] // Scribd. URL: https://ru.scribd.com/document/148361294/A-Newly-Discovered-Urga-Edition-of-the-Tibetan-Kanjur/ (дата обращения 10.02.2019).

A Catalogue of the Tibetan Manuscripts and Block Prints in the Library of the Hungarian Academy of Sciences by Gergely Orosz (2009) : in 3 vol. Comp. by G. Orosz, ed. by D. Kinga. Budapest : Published by the library of the Hungarian Academy of sciences. Vol. 2. $894 \mathrm{p}$.

Taube, M. (1966a) Tibetische Handschriften und Blockdrucke : Verzeichnis der Orientalischen Handschriften in Deutschland / im Einvernehmen mit der Deutschen Morgenleandischen Gesellschaft herausgegeben von Wolfgang Voigt / Im Auftrag der Akademie der Wissenschaften in Goettingen. Teil 1-4. Wiesbaden : Franz Steiner Verlag GMBH. T. 1. $371 \mathrm{c}$.

Taube, M. (1966b) Tibetische Handschriften und Blockdrucke : Verzeichnis der Orientalischen Handschriften in Deutschland / im Einvernehmen mit der Deutschen Morgenleandischen Gesellschaft herausgegeben von Wolfgang Voigt / Im Auftrag der Akademie der Wissenschaften in Goettingen. Teil 1-4. Wiesbaden : Franz Steiner Verlag GMBH. T. 3. 995 c.

Taube, M. (1966c) Tibetische Handschriften und Blockdrucke : Verzeichnis der Orientalischen Handschriften in Deutschland / im Einvernehmen mit der Deutschen Morgenleandischen Gesellschaft herausgegeben von Wolfgang Voigt / Im Auftrag der Akademie der Wissenschaften in Goettingen. Teil 1-4. Wiesbaden : Franz Steiner Verlag GMBH. T. 4. 1280 c.

Дата поступления: 01.03.2019 2.

\section{REFERENCES}

Adyg-Tulush, D. K. (2014) Skif khun turk urankhainyn khuulgaazyn tyvalary [Mystical Tuva - the Scythians, Huns, Turks of Uryankhay]. Kyzyl, OOO «Kooperativ «Zhurnalist». 152 p. (In Tuv.).

Bazarov, A. A. (2017) Literatura siddkhanta (dubta) v buriatskikh monastyriakh na rubezhe XIX-XX v. [The literature of Siddhanta (doubt) in the Buryat monasteries at the turn of 20th century]. Vostokovedenie, vol. 12, no. 5, pp. 105-111. (In Russ.).

Bazarov, A. A. and Rinchinov O. S. (2016) Buddiiskaia knizhnaia povsednevnost' Buriatii: Geoinformatsionnye podkhody k rekonstruktsii kul'turnogo iavleniia [Books in everyday life of Buddhist Buryatia: Geoinformational approaches to reconstructing a cultural phenomenon]. Bibliosfera, no. 1, pp. 11-18. (In Russ.). 
НОВЫЕ ИССЛЕДОВАНИЯ ТУВЫ

www.nit.tuva.asia

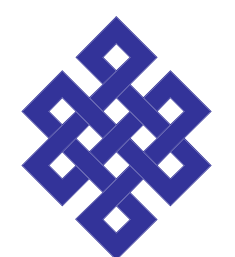

\section{THE NEW RESEARCH OF TUVA}

Novye issledovaniia Tuvy

Bicheldei, U. P. (2011) Sobranie buddiiskikh rukopisei i ksilografov v Fondakh Natsional'nogo muzeia Respubliki Tyva kak pamiatnik dukhovnoi kul'tury Tuvinskogo naroda [A collection of Buddhist manuscripts and xylographs in the collections of the National Museum of the Republic of Tuva as a monument of the spiritual culture of the Tuvan people]. In: Pamiat' mira: Istoriko-dokumental'noe nasledie buddizma [Memory of the world: Historical and documentary heritage of Buddhism] : Proceedings of the international scientific-practical conference: collection of articles / ed. by V. V. Minaev. Moscow, Rossiiskii gosudarstvennyi gumanitarnyi universitet. 229 p. Pp. 228-233. (In Russ.).

Vanchikova, Ts. P. (2012) Buddologicheskie issledovaniia v Tsentre vostochnykh rukopisei i ksilografov IMBT SO RAN [Buddhist studies at the Center of Oriental manuscripts and woodcuts of IBT SB RAS]. Vestnik Buriatskogo Nauchnogo Tsentra SO RAN, no. 3 (7), pp. 243-258. (In Russ.).

Vorob'eva-Desiatovskaia, M. I. and Savitskii, L. S. (1981) Tibetskii fond LO IVAN SSSR [The Tibetan collection at LO IVAN USSR]. In: Pis'mennye pamiatniki Vostoka: Istoriko-filologicheskie issledovaniia. Ezhegodnik 1974 [Written monuments of the East: Historical and philological studies. Yearbook 1974]. Moscow, Nauka; GRVL. 139 p. Pp. 139-153. (In Russ.).

Elikhina, Iu. I. and Samosiuk, K. F. (2015) «Obitel' miloserdiia». Iskusstvo tibetskogo buddizma [An "abode of mercy": The art of Tibetan Buddhism] : exhibition catalogue. St. Petersburg, State Hermitage Publishing House. 379 p. (In Russ.).

Zorin, A. V. (2014) Tibetskii fond Instituta Vostochnykh rukopisei RAN: Iz istorii formirovaniia i katalogizatsii (1917-2013 gg.) [The Tibetan collection at the Institute of Oriental manuscripts, Russian Academy of Sciences: From the history of acquisition and cataloguing (1917-2013).]. In: Strany i narody Vostoka [The countries and peoples of the East] / ed. by I. F. Popova and T. D. Skrynnikova. Moscow, Nauka, Vostochnaia literatura. 143 p. Pp. 143-168. (In Russ.).

Zorin, A. V. (2017) Katalog sochinenii tibetskogo buddiiskogo kanona iz sobraniia IVR RAN [A catalogue of the writings of the Tibetan Buddhist canon from the collections of the IOM RAS]. Issue 1: Kagyur and Tengyur / ed. by A. V. Zorin. St. Petersburg, Peterburgskoe Vostokovedenie. 512 p. (In Russ.).

Krivdik, V. (1990) Taina peshchery [The mystery of the cave]. Tuvinskaia Pravda, no. 23, p. 4. (In Russ.).

Mongush, M. V. (1992) Lamaizm v Tuve [Lamaism in Tuva]. Kyzyl, Tuvan book publ. house. 126 p. (In Russ.).

Mongush, M. V. (2001) Istoriia buddizma v Tuve (vtoraia polovina VI-konets XX v.) [A history of Buddhism in Tuva from the latter half of 6th to the end of 20th century)]. Novosibirsk, Nauka. 114 p. (In Russ.).

Muzraeva, D. N. (2010) O sostave i soderzhanii kollektsii buddiiskikh pis'mennykh pamiatnikov, sokhranivshikhsia v Kalmykii k nachalu XX v. [On the composition and content of collections of Buddhist written monuments preserved in Kalmykia by the early 20th century]. In: Pamiat' mira: Istoriko-dokumental'noe nasledie buddizma [Memory of the world: Historical and documentary heritage of Buddhism]: Proceedings of an international conference / ed. by V. V. Minaev. Moscow, Rossiiskii gosudarstvennyi gumanitarnyi universitet. 233 p. Pp. 233-240. (In Russ.).

Sazykin, A. G. (1992) Sobranie mongol'skikh rukopisei i ksilografov iz fondov Tuvinskogo respublikanskogo kraevedcheskogo muzeia im. 60 Bogatyrei [Mongolian manuscripts and woodcuts from the collections of the Tuvan Republican Museum of Local History]. In: Tiurkskie i mongol'skie pis'mennye pamiatniki [Turkic and Mongolian manuscripts] / ed. by S. G. Kliashtornyi and Iu. A. Petrosian. Moscow, Nauka, Vostochnaia literature Publ. 151 p. Pp. 45-59. (In Russ.).

Sumba, R. P. (2004) Shamanskie teksty na tibetskom iazyke v fondakh Natsional'nogo muzeia im. Aldan-Maadyr Respubliki Tuva [Shamanic texts in Tibetan in the funds of the Aldan-Maadyr National Museum of the Republic of Tuva]. In: Biblioteki v zhizni obshchestva, razvitii nauki i obrazovaniia [Libraries in society, science and education] : Proceedings of an international conference / ed. by O. V. Fentsel'. Kyzyl, Variant. 64 p. Pp. 55-58. (In Russ.).

Sumba, R. P. (2005) Tibetskie rukopisi i ksilografy v fondakh Natsional'nogo muzeia im. Aldan-Maadyr Respubliki Tuva [Tibetan manuscripts and woodcuts in the collections of the Aldan-Maadyr National Museum of the Republic of Tuva]. In: 48th Permanent International Altaistic Conference, Moscow 10-15 July / Ed. by E. V. Boikova and R. B. Rybakov / Asiatische Forschungen, vol. 150. Wiesbaden, Harrassowitz Verlag. 353 p. Pp. 305-309. (In Russ.).

Chyrgalan, S. Iu. (2017) Buddiiskie monastyri v Tuve do nachala XX veka [Buddhist monasteries in Tuva before 20th century]. Molodoi uchenyi, no. 6, pp. 384-387 [online] Available at: https://moluch.ru/archive/140/39539/ (access date: 25.02.2019). (In Russ.).

Bethlenfalvy, G. A (1980) Catalogue of the Urga Kanjur in the Prof. Raghuvira Collection at the International Academy of Indian Culture. Vol. 246 / њata-Pițaka Series: Indo-Asian Literatures. New Delhi, Published by International Academy of Indian Culture. 319 p.

Chandra, L (1980) A newly Discovered Urga Edition of the Tibetan Kanjur. Scribd [online] Available at: https://ru.scribd. com/document/148361294/A-Newly-Discovered-Urga-Edition-of-the-Tibetan-Kanjur/ (access date: 10.02.2019).

A Catalogue of the Tibetan Manuscripts and Block Prints in the Library of the Hungarian Academy of Sciences by Gergely Orosz (2009) : in 3 vol. Comp. by G. Orosz, ed. by D. Kinga. Budapest : Published by the library of the Hungarian Academy of sciences. Vol. 2.894 p.

Taube, M. (1966a) Tibetische Handschriften und Blockdrucke : Verzeichnis der Orientalischen Handschriften in Deutschland / im Einvernehmen mit der Deutschen Morgenleandischen Gesellschaft herausgegeben von Wolfgang Voigt / Im Auftrag der Akademie der Wissenschaften in Goettingen. Teil 1-4. Wiesbaden : Franz Steiner Verlag GMBH. T. 1. 371 p. (In Germ.). 
Taube, M. (1966b) Tibetische Handschriften und Blockdrucke : Verzeichnis der Orientalischen Handschriften in Deutschland / im Einvernehmen mit der Deutschen Morgenleandischen Gesellschaft herausgegeben von Wolfgang Voigt / Im Auftrag der Akademie der Wissenschaften in Goettingen. Teil 1-4. Wiesbaden : Franz Steiner Verlag GMBH. T. 3. 995 p. (In Germ.).

Taube, M. (1966c) Tibetische Handschriften und Blockdrucke : Verzeichnis der Orientalischen Handschriften in Deutschland / im Einvernehmen mit der Deutschen Morgenleandischen Gesellschaft herausgegeben von Wolfgang Voigt / Im Auftrag der Akademie der Wissenschaften in Goettingen. Teil 1-4. Wiesbaden : Franz Steiner Verlag GMBH. T. 4. 1280 p. (In Germ.).

Submission date: 01.03.2019. 